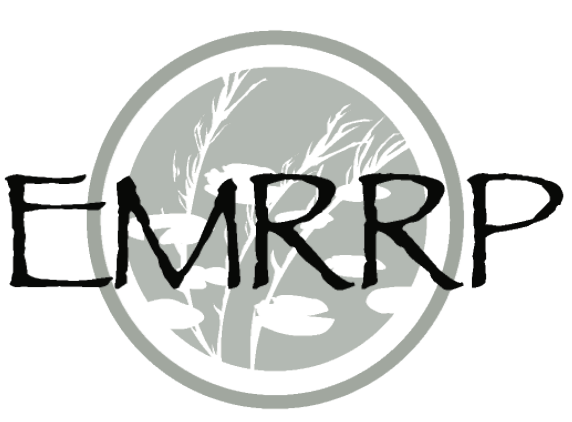

\title{
Aligning Ecological Model Development with Restoration Project Planning
}

\author{
by S. Kyle McKay ${ }^{1}$, Nate Richards ${ }^{2}$, and Todd S. Swannack ${ }^{3}$
}

OVERVIEW: Models contribute vitally to ecosystem conservation and restoration decisionmaking. Restoration project planning in the U.S. Army Corps of Engineers (USACE) may proceed rapidly from project conception to feasibility-level design through a series of sequential decisions, which iteratively articulate the federal interest, quantify the benefits and costs of competing management actions, and reduce uncertainty in project outcomes. In this process, numerical tools are applied to purposes as diverse as enhancing understanding of complex ecological processes, comparing alternative management actions, and building trust and buy-in among stakeholders. Owing to the relatively short planning horizon (typically three years) and high complexity of USACE projects (typically large-scale or watershed-scale actions), there is a perception that ecological models cannot be developed during project planning. This technical note addresses this misconception through three mechanisms. First, the ecological model development process is presented along with examples of modeling misconceptions observed in other agencies and management contexts. Second, common uses of ecological models are explicitly mapped to the USACE planning processes, timelines, and milestones. Third, an example of ecological model development and review is presented for an ongoing USACE watershed restoration study in Proctor Creek, Atlanta, Georgia. From these three lines of evidence, we conclude that ecological model development is not only possible in USACE studies, it is integral and complementary to the goals of the agency's planning process.

ECOLOGICAL MODEL DEVELOPMENT: Ecological models have a long history of informing both basic research (e.g., Lotka-Volterra models of predator-prey dynamics) and applied conservation and management (e.g., sustainable harvest and endangered species population viability). Unlike modeling in some disciplines, ecological modeling's objective is not always predicting the absolute behavior of a system (i.e., the "truth"), but often increasing understanding of complex system dynamics or comparing the relative merits of management alternatives (Starfield 1997). These broad uses often imply that models are developed for projectspecific needs, and numerous authors have emphasized the critical importance of tailoring models to a given set of needs, questions, hypotheses, and purposes (e.g., Nicholson et al. 2002, Grant and Swannack 2008, Schmolke et al. 2010). For example, while synthesizing findings from a special issue on ecological models, Turner and Carpenter (2017) reinforce the importance

\footnotetext{
${ }^{1}$ U.S. Army Engineer Research and Development Center (ERDC), Environmental Laboratory (EL), New York, NY, Phone: 601415-7160, Kyle.McKay@usace.army.mil

${ }^{2}$ U.S. Army Corps of Engineers (USACE), Rock Island District (MVR), Rock Island, IL, Phone: 309-794-5286,

Nathan.S.Richards@usace.army.mil

${ }^{3}$ ERDC-EL, Austin, TX, Phone: 601-415-3509, Todd.S.Swannack@usace.army.mil
} 
of project-specific model development and even question the utility of readily available models, stating:
Another clear message across the set of papers is that healthy skepticism is required when using readily available models or datasets. Models built for one purpose may be poor tools for another, and deciding whether to use an existing model or develop a new one requires careful thought. Ease of access is not a sufficient reason to apply any given model. Models must be matched to their purpose, and ultimately, we must know how the systems we study work.

Owing to a model's role as a "problem-solving tool," the ecological model development process is often emphasized over the tool or result the model provides (Starfield 1997). Typically, model development proceeds through four basic steps of conceptualization, quantification, evaluation, and application (Figure 1; Grant and Swannack 2008, Swannack et al. 2012). These steps are iteratively applied to develop models ranging from single-use, rudimentary tools (e.g., a spreadsheet constructed during a meeting to estimate rough order of magnitude) to robust, broadly applicable, high-fidelity tools for examining complex ecosystems (e.g., software for forecasting food web dynamics). In fact, a growing consensus among modelers indicates that simple models and rapid prototypes are a crucial mechanism for development of more complex models (Starfield 1997, Nicholson et al. 2002, Jakeman et al. 2006). Modelers must iteratively evaluate whether the benefits provided by model complexity are worth the added costs of development, which can only be answered relative to the specified model objectives and outcomes. Further, the audience must also be considered; during each developmental phase, model outcomes may be communicated to diverse audiences ranging from technical experts to interested citizens.

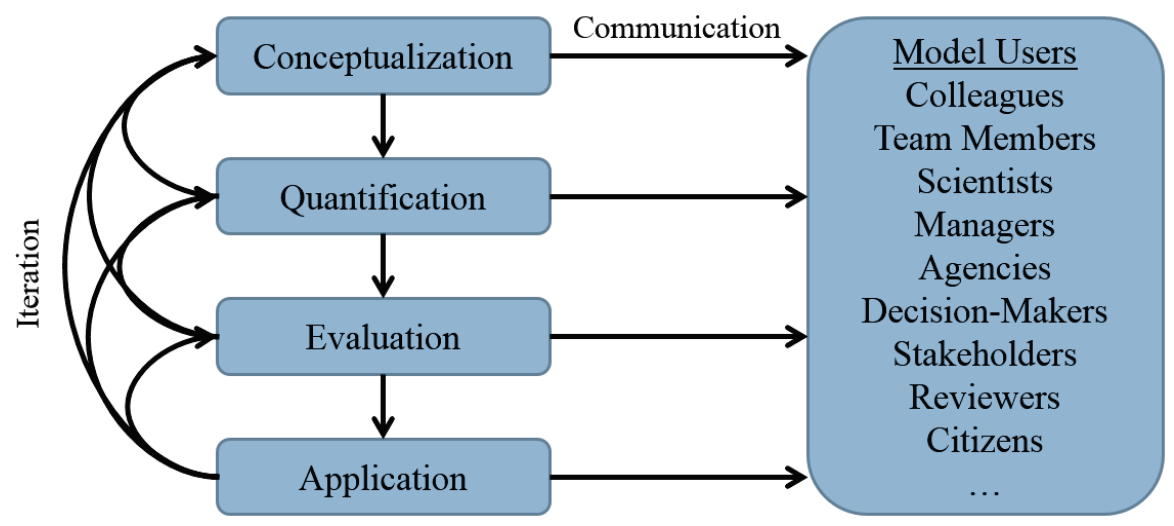

Figure 1. Ecological model development process (after Grant and Swannack 2008).

Ecological models can play a role in informing countless aspects of conservation, management, and restoration decisions. However, numerical models are often underutilized by ecosystem and water managers, and numerous misconceptions regarding models exist (Table 1). A variety of guidance documents and best practices have been recommended to overcome these perceptions of modeling (Starfield 1997, Grant and Swannack 2008, Addison et al. 2013), particularly with respect to collaborative model development (Nicholson et al. 2002, Langsdale et al. 2013). 
Table 1. An abbreviated summary of common misconceptions about ecological models. Misconceptions are taken primarily from Starfield (1997), but also informed by Nicholson et al. (2002), Grant and Swannack (2008), Langsdale et al. (2013), and Addison et al. (2013).

\begin{tabular}{|c|c|}
\hline Misconception & Pragmatic Responses to These Fallacies \\
\hline $\begin{array}{l}\text { A model cannot be built } \\
\text { with incomplete } \\
\text { understanding. }\end{array}$ & $\begin{array}{l}\text { Managers make decisions with incomplete information all the time (Schultz et al. } \\
\text { 2010), which is added incentive for model-building as a statement of current best } \\
\text { understanding. Furthermore, model development often includes quantification of } \\
\text { model sensitivity that helps parse out how much (or how little) impact incomplete } \\
\text { understanding has on decisions made with model results. }\end{array}$ \\
\hline $\begin{array}{l}\text { A model cannot be } \\
\text { applied until it has been } \\
\text { validated or proven } \\
\text { "accurate." }\end{array}$ & $\begin{array}{l}\text { While some applications require accuracy (e.g., flood forecasting), ecological model } \\
\text { validation may be challenging in many cases due to uncertainties in ecological } \\
\text { understanding, inherent stochasticity in system function, or lack of available } \\
\text { validation data. Although validation is preferable, the process of constructing a } \\
\text { model often leads to key insights about system functionality, and unvalidated tools } \\
\text { can still serve a valuable role of relative comparison of management actions (e.g., } \\
\text { Is alternative A better than alternative B?) }\end{array}$ \\
\hline $\begin{array}{l}\text { A model must be as } \\
\text { realistic as possible. }\end{array}$ & $\begin{array}{l}\text { If models are constructed as "purposeful representations of reality," then designing } \\
\text { the leanest possible model is appropriate. Critical variables should be identified and } \\
\text { joined in the most simple of formal structures. Extreme inputs (e.g., reasonable } \\
\text { minimum and maximums) can be used to bound a problem and explore the relative } \\
\text { influence of parameterization on outcomes. }\end{array}$ \\
\hline $\begin{array}{l}\text { Models can only be used } \\
\text { or understood by } \\
\text { modelers. }\end{array}$ & $\begin{array}{l}\text { Ecosystem and water managers develop countless conceptual and numerical } \\
\text { tools for informing decisions ranging from basic maintenance (e.g., Is rain } \\
\text { interrupting the week's operations?) to budgets (e.g., What are investment } \\
\text { priorities if a grant is not funded?) to complex ecological decisions (e.g., How } \\
\text { will an imperiled fish respond to a reservoir flow release?). These tools and } \\
\text { their developers are models and modelers, respectively (whether or not the } \\
\text { user considers them so). }\end{array}$ \\
\hline $\begin{array}{l}\text { Models are only used to } \\
\text { make predictions. }\end{array}$ & $\begin{array}{l}\text { While predictions are a useful outcome of model development, the modeling } \\
\text { process can lead to more formal documentation of ecological knowledge, } \\
\text { agreement on key variables and processes, clarity about project objectives and } \\
\text { alternatives, development of trust among team members, identification of critical } \\
\text { patterns or cycles, an additional line of evidence for decision making, clear } \\
\text { documentation of key uncertainties or project risks, and can inform appropriate } \\
\text { adaptive management actions and decision points. }\end{array}$ \\
\hline $\begin{array}{l}\text { Modeling is time- } \\
\text { consuming and } \\
\text { expensive. }\end{array}$ & $\begin{array}{l}\text { Models may be developed in days, months, or decades. Confidence and } \\
\text { accuracy change, but rapid model development is a common objective and } \\
\text { outcome. }\end{array}$ \\
\hline
\end{tabular}

MODELS AND USACE PLANNING: Within the USACE, the planning process provides a reliable, transparent framework for making ecosystem restoration decisions (USACE 2000). Since 2012, a modernization of the planning process has emphasized a shift to the "SMART Planning" paradigm of Specific, Measurable, Attainable, Risk-Informed, and Timely decision-making (USACE 2012). This SMART Planning framework was implemented to reduce the time and cost of planning studies (targeting less than three years and $\$ 3 \mathrm{M}$ ) by iteratively making coordinated decisions across the District, Division, and Headquarters teams (three levels of vertical integration) ${ }^{1}$. The process demarcates four key milestones (Figure 2; USACE 2012, Dalton 2017), with the primary technical activities occurring in the first three decision-making points.

\footnotetext{
${ }^{1}$ https://planning.erdc.dren.mil/toolbox/
} 


\begin{tabular}{|c|c|c|c|}
\hline SCOPING & $\begin{array}{l}\text { ALTERNATIVE } \\
\text { FORMULATION } \\
\text { \& ANALYSIS }\end{array}$ & $\begin{array}{l}\text { FEASIBILITY-LEVEL } \\
\text { ANALYSIS }\end{array}$ & $\begin{array}{l}\text { REPORT } \\
\text { APPROVAI }\end{array}$ \\
\hline $\begin{array}{r}\text { ALTERNATIVES } \\
\text { MILESTONE }\end{array}$ & $\begin{array}{r}\text { TENTATIVELY } \\
\text { SELECTED PLAN (TSP) } \\
\text { MILESTONE }\end{array}$ & $\begin{array}{r}\text { AGENCY } \\
\text { DECISION } \\
\text { MILESTONE } \\
\end{array}$ & $\begin{array}{l}\text { CHIEF'S } \\
\text { REPORT }\end{array}$ \\
\hline
\end{tabular}

Figure 2. USACE SMART Planning process (USACE 2012, Dalton 2017).

Specific technical deliverables are associated with each decision milestone (USACE 2012, USACE 2017), many of which align with common ecological modeling objectives (Table 2). Importantly, USACE has long recognized the role of high quality ecological models in planning, and the agency requires that all models be appropriately reviewed through the model certification process (USACE 2005, USACE 2011). Planning teams often assume that the relatively rapid SMART Planning timeline (typically three years) precludes ecological model development and certification. However, the striking similarities in these parallel processes contradict this common misconception. In fact, ecological model development could be a mechanism for facilitating project-specific decision-making (Starfield 1997), particularly if an explicitly participatory approach is applied (Langsdale et al. 2013).

\begin{tabular}{|c|c|c|}
\hline $\begin{array}{l}\text { Planning } \\
\text { Milestone }\end{array}$ & Common Planning Goals & $\begin{array}{l}\text { Potential Role of Ecological Models and } \\
\text { the Model Development Process }\end{array}$ \\
\hline $\begin{array}{l}\text { Alternatives } \\
\text { Milestone }\end{array}$ & 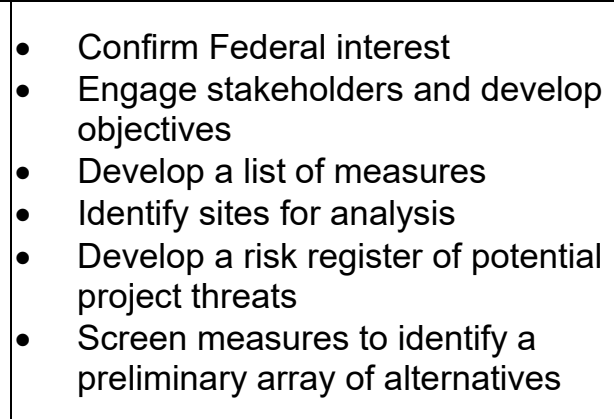 & 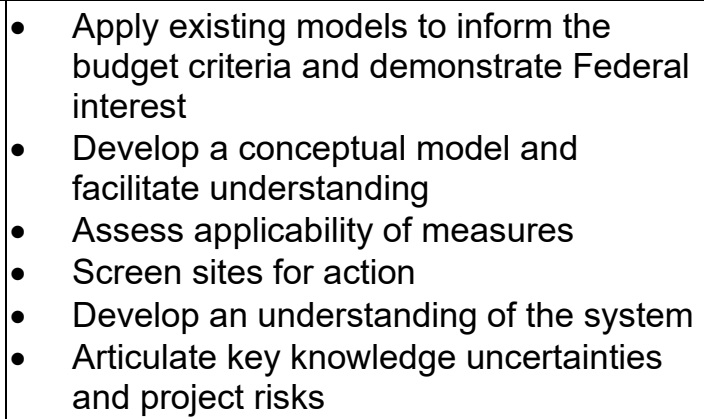 \\
\hline $\begin{array}{l}\text { Tentatively } \\
\text { Selected Plan } \\
\text { (TSP) Milestone }\end{array}$ & $\begin{array}{l}\text { - Develop alternatives addressing } \\
\text { objectives } \\
\text { - Quantify project benefits } \\
\text { - Compare alternatives to make a } \\
\text { recommendation }\end{array}$ & 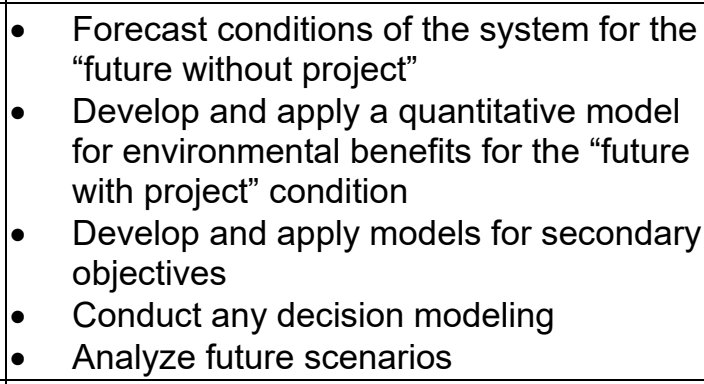 \\
\hline $\begin{array}{l}\text { Agency } \\
\text { Decision } \\
\text { Milestone } \\
\text { (ADM) }\end{array}$ & $\begin{array}{l}\text { - Confirm and refine the } \\
\text { recommended alternative } \\
\text { - Examine the sensitivity of the } \\
\text { recommended decision } \\
\text { - Examine potential scenarios (e.g., } \\
\text { land use or climate change) }\end{array}$ & $\begin{array}{l}\text { - Analyze sensitivity of decisions to } \\
\text { assumptions and uncertainty } \\
\text { Inform monitoring and adaptive } \\
\text { management planning }\end{array}$ \\
\hline
\end{tabular}


PROCTOR CREEK CASE STUDY ${ }^{1}$ : The previous section highlights that ecological model development is often assumed to be incommensurate with SMART Planning timelines, even though the parallel processes could be mutually beneficial. Here, a USACE restoration project case study is applied to demonstrate that model development and certification are not only possible within SMART Planning timelines, but also valuable to project decision-making.

In partnership with the City of Atlanta and thirteen federal agencies, the Mobile District of the U.S. Army Corps of Engineers is planning an urban stream restoration in Proctor Creek, Atlanta, Georgia. Proctor Creek presents a classic example of the ecological degradation common in urban streams with its headwaters draining the most urbanized portions of downtown Atlanta along with major industrial zones such as the railyard. Beginning in October 2015, this watershed-scale restoration project required the project development team to rapidly proceed through the SMART Planning milestones in a scientifically defensible manner at a large spatial scale (more than 13 miles of stream and riparian habitat). Early project team meetings and a stakeholder charrette identified four primary objectives: (1) improve in-channel conditions suitable for a diversity of aquatic organisms, (2) improve riparian conditions supportive of a diverse aquatic and riparian community, (3) restore flow regimes to best attainable conditions achievable in altered urban environments, and (4) promote an interconnected system resilient to foreseen and unforeseen disturbances. While many stream assessment tools exist, no comprehensive, integrated model was available to inform all four objectives simultaneously. Thus, the team elected to construct an ecological model tailored to the project's specific objectives and needs. The following sections briefly describe the joint process of model development and project planning with an emphasis on the modeling process, not the model. Additional model details can be found in the study reports or McKay et al. (2018ab).

A two-phase model development process was applied to align model development explicitly with the information needs of the Alternatives and TSP Milestones. Figure 3 outlines the parallel steps in both model development and the SMART Planning process. For the Alternatives Milestone, modeling needs included development of a conceptual model to guide restoration decisions, assessing the applicability of a diversity of potential restoration measures (e.g., streambank protection, fish passage improvement, hydrologic restoration), and rapidly screening restoration sites. Four sub-models were developed explicitly addressing the project objectives, and a broader numerical approach was outlined to combine these four metrics in the Phase 1 Proctor Creek Ecological Model (PCEM1). Based on a rapid field assessment (i.e., one week), the watershed was sub-divided into 46 reaches and restoration opportunities were identified in 38 reaches and at 15 flow restoration sites. PCEM1 was applied to screen more than 1,000,000 combinations of sites and actions to a narrowed array of 19 sites for continued analysis, which were agreed upon by the vertical team at the Alternatives Milestone.

\footnotetext{
${ }^{1}$ This project is an ongoing feasibility study, and this summary does not necessarily reflect project decision-making or District recommendations. The project website should be consulted for all information.

http://www.sam.usace.army.mil/Missions/Planning-Environmental/Environment-Resources/Inland-Environment/Proctor-CreekFeasibility-Study/
} 


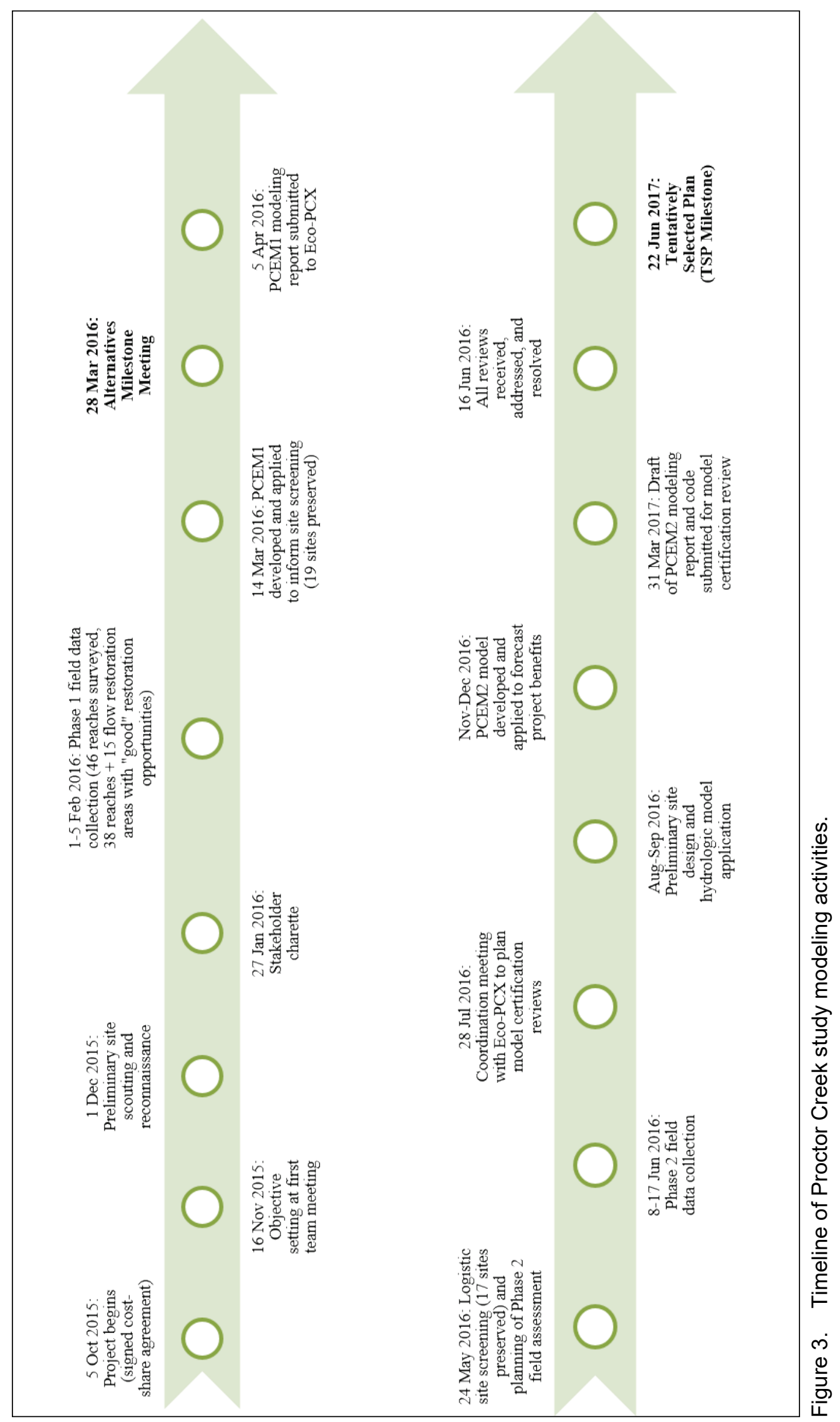


Following agreement at the Alternatives Milestone, a second phase of model development was pursued to meet modeling needs for the TSP Milestone, which included computing environmental benefits of restoration actions, informing feasibility-level design, and facilitating restoration decision-making. The four sub-models were preserved from Phase 1, but each was refined to better reflect project sub-objectives. For instance, the project objective associated with instream condition was decomposed into sub-objectives related to geomorphic condition, sediment loading, and instream habitat. As the project team clarified its intent, models were refined simultaneously. Because of the reduced number of sites (19 rather than 53), more detailed data collection was possible at the remaining sites, which reduced project uncertainties. The refined ecological models (PCEM2) were then applied to not only inform project recommendations, but also refine feasibility-level designs.

Three pertinent observations may be made from the model development process in Proctor Creek. First, models were developed specifically to measure project objectives, which provided a clear and transparent mechanism for communicating with the project sponsor, stakeholders, and other interested parties. Second, the phased, iterative approach to model development mapped clearly to the SMART Planning Milestones with a prototype informing the Alternatives Milestone and a more sophisticated toolkit applied for the TSP Milestone. Third, model development was pursued in open and frequent communication with the Ecosystem Restoration Planning Center of Expertise (Eco-PCX), the organization that administers the model review and certification process. The Eco-PCX was notified of the intent to develop a model shortly after the stakeholder charrette four months into the project. Draft model documentation and model structure were frequently discussed with the review team to avoid any model components that may be prohibited by policy. Model review was coordinated and planned such that when the models and reports were complete, all reviewers were immediately ready to begin. While many aspects contributed to the successful development of a model in this rapid timeline (e.g., a motivated planning team, significant local knowledge, small basin size), these three factors were crucial to the efficient alignment with SMART Planning Milestones.

As described in Table 1, ecological model development is often misconceived as a slow process with impractical, academic motivations. However, the Proctor Creek study provides one (of many) examples where ecological model development was practically conducted within the confines of demanding applied project timelines. Parallel project planning and model development resulted in mutually beneficial outcomes, such as project-specific tools customized to restoration objectives, tools designed around evolving project needs (e.g., screening vs. benefits assessment vs. preliminary design), numerical tools available for future applications (e.g., tools were subsequently adapted for use in the Hudson-Raritan Estuary, McKay et al. 2017), and shared understanding of needs between the "modelers" and the "practitioners" (i.e., both group participated in all planning and modeling steps).

CONCLUSIONS: Ecological model development is a technical process that often combines ecological knowledge obtained from subject matter experts, computation necessary for numerically executing a model, and decision-making requirements of managers and planners. However, there is a perception that these challenges preclude the use of ecological models in management decisionmaking, which is largely unfounded (Starfield 1997, Addison et al. 2013). Ecological models can be developed over nearly any timeframe (e.g., a day, a month, a year, or a decade), albeit with 
shifts in ecological realism, predictive accuracy, technical review, and stakeholder buy-in. These shifts do not invalidate the model results, however, when applied at appropriate stages of the project and used to inform more focused and detailed subsequent modeling efforts.

This paper focused on overcoming the misconception that ecological model development is not possible in decision-relevant timeframes. The authors presented the following three lines of evidence that decision-making and modeling processes align efficiently: 1) a direct response to common misconceptions about models, 2) a direct mapping of model applications to USACE SMART Planning timelines, and 3) an example of model development for a USACE study. The USACE SMART Planning process was highlighted here, but the same model development principles also apply to other decision-making frameworks (e.g., Gregory and Keeney 2002). Ecological model development is an iterative process that seeks to refine details and knowledge as needed, which seamlessly parallels typical decision-making processes across ecosystem and water management.

ADDITIONAL INFORMATION: This technical note was supported by the Ecosystem Management and Restoration Research Program (EMRRP). The USACE Proponent for the EMRRP Program is Ms. Mindy Simmons and the Technical Director is Dr. Al Cofrancesco. Technical reviews and suggestions for improvement by Dr. Safra Altman, Ms. Brook Herman (ERDC-EL), Ms. Meredith Ladart, Mr. Brian Zettle (USACE Mobile), Mr. Peter Weppler (USACE New York), Ms. Jodi Creswell (USACE St. Paul), Mr. Greg Miller (USACE Ecosystem Restoration Planning Center of Expertise), and Mr. Jeff Lin (USACE Headquarters) are greatly appreciated.

For additional information, contact Dr. Kyle McKay (601-415-7160, Kyle.McKay@, usace.army.mil), or the manager of the Ecosystem Management and Restoration Research Program, Dr. Trudy Estes (601-634-2125, Trudy.J.Estes@usace.army.mil). This technical note should be cited as follows:

McKay S. K., N. Richards, and T. S. Swannack. 2019. Aligning ecological model development with restoration project planning. EMRRP Technical Notes Collection. ERDC/TN EMRRP-SR-89. Vicksburg, Mississippi: U.S. Army Engineer Research and Development Center. http://cw-environment.usace. army.millebal

\section{REFERENCES}

Addison, P. F. E., L. Rumpff, S. S. Bau, J. M. Carey, Y. N. Chee, F. C. Jarrad, M. F. McBride, and M. A. Burgman. 2013. Practical solutions for making models indispensable in conservation decision-making. Diversity and Distributions 19:490-502.

Crawford B. A., R. A. Katz, and S. K. McKay. 2017. Engaging stakeholders in natural resource decision-making. ERDC TN-EMRRP-83. Vicksburg, Mississippi: U.S. Army Engineer Research and Development Center.

Dalton J. C. 2017. Further advancing project delivery efficiency and effectiveness of USACE Civil Works. Washington, DC: Director of Civil Works, CECW-ZB, Headquarters, U.S. Army Corps of Engineers.

Grant W. E. and T. M. Swannack. 2008. Ecological modeling: A common-sense approach to theory and practice. Malden, MA: Blackwell Publishing. 
Gregory R. S., and R. L. Keeney. 2002. Making smarter environmental management decisions. Journal of the American Water Resources Association 38(6):1601-1612.

Jakeman A. J., R. A. Letcher, and J. P. Norton. 2006. Ten iterative steps in development and evaluation of environmental models. Environmental Modelling and Software 21:602-614.

Langsdale S., A. Beall, E. Bourget, E. Hagen, S. Kudlas, R. Palmer, D. Tate, and W. Werick. 2013. Collaborative modeling for decision support in water resources: Principles and best practices. Journal of the American Water Resources Association 49(3):629-638.

McKay S. K., M. Reif, J. N. Conyngham, and D. Kohtio. 2017. Barrier prioritization in the tributaries of the Hudson-Raritan Estuary. ERDC TN-EMRRP-SR-82. Vicksburg, MS: U.S. Army Engineer Research and Development Center.

McKay S. K., B. A. Pruitt, B. Zettle, N. Hallberg, C. Hughes, A. Annaert, M. Ladart, and J. McDonald. 2018a. Proctor Creek Ecological Model (PCEM): Phase 1 Site screening. ERDC EL TR-18-11. Vicksburg, MS: U.S. Army Engineer Research and Development Center.

McKay, S. K., B. A. Pruitt, B. A. Zettle, N. Hallberg, V. Moody, A. Annaert, M. Ladart, M. Hayden, and J. McDonald. 2018b. Proctor Creek Ecological Model (PCEM): Phase 2 benefits analysis. ERDC EL TR-18-11. Vicksburg, MS: U.S. Army Engineer Research and Development Center.

Nicholson, C. R., A. M. Starfield, G. P. Kofinas, and J. A. Kruse. 2002. Ten heuristics for interdisciplinary modeling projects. Ecosystems 5:376-384.

Schmolke A., P. Thorbek, D. L. DeAngelis, and V. Grimm. 2010. Ecological models supporting environmental decision making: A strategy for the future. Trends in Ecology and Evolution 25:479-486.

Schultz M. T., K. N. Mitchell, B. K. Harper, and T. S. Bridges. 2010. Decision Making Under Uncertainty. ERDC TR-10-12. Vicksburg, MS: U.S. Army Engineer Research and Development Center.

Starfield, A. M. 1997. A pragmatic approach to modeling for wildlife management. Journal of Wildlife Management 61(2):261-270.

Swannack T. M., J. C. Fischenich, and D. J. Tazik. 2012. Ecological Modeling Guide for Ecosystem Restoration and Management. ERDC/EL TR-12-18. Vicksburg, MS: U.S. Army Engineer Research and Development Center.

Turner, M. G. and S. R. Carpenter. 2017. Ecosystem modeling for the $21^{\text {st }}$ century. Ecosystems 20:211-214.

U.S. Army Corps of Engineers (USACE). 2000. Planning Guidance Notebook. ER-1105-2-100. Washington, DC. 2005. Planning Models Improvement Program: Model Certification. EC-1105-2-407. Washington, DC. . 2011. Assuring Quality of Planning Models. EC-1105-2-412. Washington, DC. 2012. Planning SMART Guide. PB 2012-02. Washington, DC. 2017. Feasibility Study Milestones. PB 2017-01. Washington, DC.

Yoe, C., and B. Harper. 2017. Planning Manual Part II: Risk-informed planning. 2017-R-03. Alexandria, VA: Institute for Water Resources, U.S. Army Corps of Engineers.

NOTE: The contents of this technical note are not to be used for advertising, publication, or promotional purposes. Citation of trade names does not constitute an official endorsement or approval of the use of such products. 